\title{
Histopatologia de lagartas de Spodoptera frugiperda (Lep., Noctuidae) infectadas por Bacillus thuringiensis aizawai e com ovos de Campoletis flavicincta (Hym., Ichneumonidae)
}

\author{
Histopathology of larvae of Spodoptera frugiperda (Lep., Noctuidae) infected by Bacillus thuringiensis \\ aizawai and with eggs of Campoletis flavicincta (Hym., Ichneumonidae)
}

\author{
Sônia Thereza Bastos Dequech ${ }^{\mathrm{I}}$ Lidia Mariana Fiuza $^{\mathrm{II}}$ Rogério Fernando Pires da Silva ${ }^{\mathrm{III}}$ \\ Roberta Cristina Zumba ${ }^{\mathrm{IV}}$
}

\begin{abstract}
- NOTA -
RESUMO

Spodoptera frugiperda (J. E. Smith, 1797) (Lepidoptera, Noctuidae) está entre os insetos-praga que mais danificam culturas, sendo possivel seu controle com produtos à base de Bacillus thuringiensis Berliner, 1911 (Bt). Um dos principais parasitóides de $\mathbf{S}$. frugiperda é Campoletis flavicincta (Ashmead, 1890) (Hymenoptera, Ichneumonidae). A interação de Bt aizawai e de C. flavicincta através da análise histopatológica do ovo do parasitóide em lagartas de $\boldsymbol{S}$. frugiperda infectadas foi avaliada. Lotes de lagartas de segundo instar foram analisados: 1) parasitadas e infectadas por $\boldsymbol{B t}$ aizawai (Xentari/Abbott Laboratórios do Brasil Ltda) a 0,5mg $m l^{-1}$ e 2) apenas parasitadas por C. flavicincta (controle). Todas

interaction between Bt aizawai and C. flavicincta by histopathological analysis of the egg of parasitoid in $\mathbf{S}$. frugiperda infected larvae was evaluated. Groups of second instar larvae were analyzed: 1) parasitized and infected by Bt aizawai (Xentari /Abbott Laboratórios do Brasil Ltda) at 0.5mg $\mathrm{ml}^{-1}$ and 2) only parasitized by $\boldsymbol{C}$. flavicincta (control). All the larvae were fixed in "Bouin Hollande", at intervals of 6, 12 and 24 hours after the infection. After the preparation of the larvae in paraffin blocks, histological cuts of $6 \mu \mathrm{m}$ thickness were made. The histological analysis of parasitized and infected larvae indicated no alteration in the egg of the parasitoid, as a result of the action of the bacillus. This result suggests that eggs of $\mathbf{C}$. flavicincta are not affected by Bt aizawai inside of the body of larvae of $\mathbf{S}$. frugiperda.
\end{abstract} as lagartas foram fixadas em "Bouin Hollande", em intervalos de 6,12 e 24 horas posteriores à infecção. Após o preparo das lagartas em blocos de parafina, foram efetuados cortes histológicos de 6um de espessura. A análise histológica de lagartas parasitadas e infectadas indicou não ter havido alteração no ovo do parasitóide, resultante da ação do bacilo. Esse resultado indica que ovos de $\boldsymbol{C}$. flavicincta não são afetados por Bt aizawai no interior do corpo de lagartas de S. frugiperda.

Palavras-chave: Lagarta-do-cartucho-do-milho, controle microbiano, inimigos naturais.

\section{ABSTRACT}

Spodoptera frugiperda (J. E. Smith, 1797) (Lepidoptera, Noctuidae) is one of the most important insect pests that affect several crops, and it can be controled with Bacillus thuringiensis Berliner, 1911 (Bt) products. One of the main parasitoids of $\boldsymbol{S}$. frugiperda is Campoletis flavicincta (Ashmead, 1890) (Hymenoptera, Ichneumonidae). The
Key words: Fall armyworm, microbial control, natural enemies.

Spodoptera frugiperda (J. E. Smith, 1797), conhecida na fase larval como "lagarta-do-cartucho", é o principal inseto-praga de várias culturas no Brasil, sendo que, no milho, pode causar perdas na produção de até 34\% (SILVA et al., 1997). S. frugiperda tem recebido atenção especial quanto ao desenvolvimento de métodos de controle que reduzam a aplicação de inseticidas, principal forma de controle utilizada pelos produtores. A atividade biológica dos inimigos naturais tem sido pesquisada, sendo que, dentre os inimigos naturais, o parasitóide Campoletis flavicincta

\footnotetext{
'Departamento de Defesa Fitossanitária, Universidade Federal de Santa Maria (UFSM), 97105-900, Santa Maria, RS, Brasil. Email: soniabd@terra.com.br. Autor para correspondência.

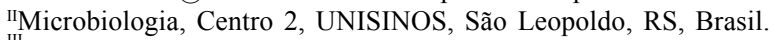

III Departamento de Fitossanidade, UFRGS, Porto Alegre, RS, Brasil.

${ }^{\mathrm{IV}}$ Curso de Agronomia, UFSM, Santa Maria, RS, Brasil.
} 
(Ashmead, 1890) tem se mostrado promissor como agente de controle de $\boldsymbol{S}$. frugiperda (CRUZ et al., 1997).

A postura de $\boldsymbol{C}$. flavicincta é realizada no interior de lagartas de primeiro e segundo ínstares de S. frugiperda, e a larva completa o ciclo alimentandose do conteúdo interno do hospedeiro. Próximo à fase de pupa, a larva do parasitóide sai do corpo da lagarta, para construir o casulo no ambiente externo (CRUZ, 1995). Apesar de poder ocorrer até quatro ovos por hospedeiro, verifica-se a emergência de apenas um indivíduo por lagarta (PATEL \& HABIB, 1987).

Outra alternativa importante aos inseticidas químicos no controle de algumas espécies de pragas é o uso de patógenos, sendo que, destes, Bacillus thuringiensis Berliner, 1911 (Bt) é altamente compatível com inimigos naturais e outros organismos não-alvos, devido à estreita especificidade dos hospedeiros (BAUER, 1995). Bt possui uma grande capacidade de produzir toxinas, dentre estas, as delta-endotoxinas, que apresentam atividade inseticida altamente específica (VALICENTE et al., 2000). Muitas cepas de $\boldsymbol{B} \boldsymbol{t}$ são classificadas em diferentes subespécies, sendo a maioria ativa contra alguns lepidópteros. As espécies do gênero Spodoptera são pouco suscetíveis à maioria das delta-endotoxinas (ARANDA et al., 1996). Segundo NAVON (1993), o controle destes insetos é difícil por não serem sensíveis a linhagens comerciais de $\boldsymbol{B}$. thuringiensis kurstaki. Por outro lado, isolados de B. thuringiensis aizawai são considerados particularmente ativos contra lagartas de Spodoptera spp. (BEEGLE \& YAMAMOTO, 1992).

As avaliações das interações entre entomopatógenos e parasitóides que ocorrem dentro de um agroecossistema podem revelar aspectos importantes, que certamente deverão maximizar os efeitos benéficos dos primeiros no Manejo Integrado de Pragas (MAGALHÃES et al., 1998).

A partir do exposto, evidencia-se a importância da realização de estudos que visem a um melhor entendimento da interação entre "parasitóidepatógeno-hospedeiro". O presente trabalho objetivou avaliar possível influência de Bt aizawai sobre ovos de $\boldsymbol{C}$. flavicincta em lagartas parasitadas de $\boldsymbol{S}$. frugiperda, através da análise histopatológica de tecidos.

Lagartas de quatro dias foram expostas ao parasitismo e, 24 horas após, um lote de 54 lagartas permaneceu apenas parasitado e outro de 75 lagartas foi infectado com Bt aizawai, adotando-se a metodologia citada em DEQUECH et al. (2005). Foi utilizado como fonte do entomopatógeno o produto comercial Xentari (Abbott Laboratórios do Brasil Ltda), à base de Bt aizawai, na dose de $0,5 \mathrm{mg} \mathrm{ml}^{-1}$, Concentração Letal Média (CL50) aos sete dias, determinada através da análise de Probit, pelo programa Polo-PC (LeOra Software 1987).

Lagartas oriundas de ambos os tratamentos foram fixadas por 24 horas em "Bouin Hollande", após intervalos de 6, 12 e 24 horas posteriores ao momento da infecção (usados como referência, mesmo para o lote de lagartas não infectadas), a fim de se constatar a presença de alteração no ovo de C. flavicincta, resultante da infecção por Bt aizawai. Logo a seguir, todas as lagartas foram mantidas em etanol $70 \%$ a $4{ }^{\circ} \mathrm{C}$. O preparo do material para análise histológica seguiu o descrito em FIUZA (1995), iniciando com a desidratação das lagartas em série crescente de etanol, passando para etanol + xilol, e para xilol e impregnação em parafina a $58^{\circ} \mathrm{C}$. Após a inclusão em blocos de parafina, foram efetuados os cortes histológicos a $6 \mu \mathrm{m}$ de espessura, com uso de micrótomo (Leitz Wetzlar). Os cortes foram aderidos nas lâminas com albumina. $\mathrm{O}$ material foi submetido ao tratamento com xilol, para remoção da parafina, seguido de hidratação em etanol e coloração com hematoxilina e eosina. As lâminas foram montadas com Bálsamo do Canadá e lamínula. Os tecidos, correspondentes aos tratamentos, foram observados em microscopia óptica. As medições dos ovos de $\boldsymbol{C}$. flavicincta foram realizadas com sobreposição de lâmina com escala micrométrica.

Dentre os insetos analisados histologicamente, foram encontrados ovos de $\boldsymbol{C}$. flavicincta em cinco lagartas do lote de lagartas apenas parasitadas (das 54 avaliadas) e cinco das parasitadas e infectadas (75 avaliadas) (Tabela 1). Em algumas lagartas, foi possível determinar que o(s) ovo(s) do parasitóide $\boldsymbol{C}$. flavicincta estava(m) situado(s) no final do corpo do hospedeiro. Em função da posição dos

Tabela 1 - Número de lagartas de $\boldsymbol{S}$. frugiperda parasitadas por $\boldsymbol{C}$. flavicincta e parasitadas e infectadas por $\boldsymbol{B}$. thuringiensis aizawai, distribuídas nos diferentes períodos após a infecção, nas quais foram visualizados ovos do parasitóide.

\begin{tabular}{lll}
\hline $\begin{array}{c}\text { Período após a } \\
\text { infecção }\end{array}$ & \multicolumn{1}{c}{ Parasitadas } & Parasitadas e infectadas \\
\hline 6 horas & - & $1(1)^{*}, 1(2)$ \\
12 horas & $1(1)$ & - \\
24 horas & $1(1), 1(2), 1(4), 1(2)$ & $1(2), 1(3), 1(3)$ \\
Total & 5 & 5 \\
\hline
\end{tabular}

*O número entre parênteses indica o total de ovos de $\boldsymbol{C}$. flavicincta visualizado por lagarta.

Ciência Rural, v.37, n.1, jan-fev, 2007. 


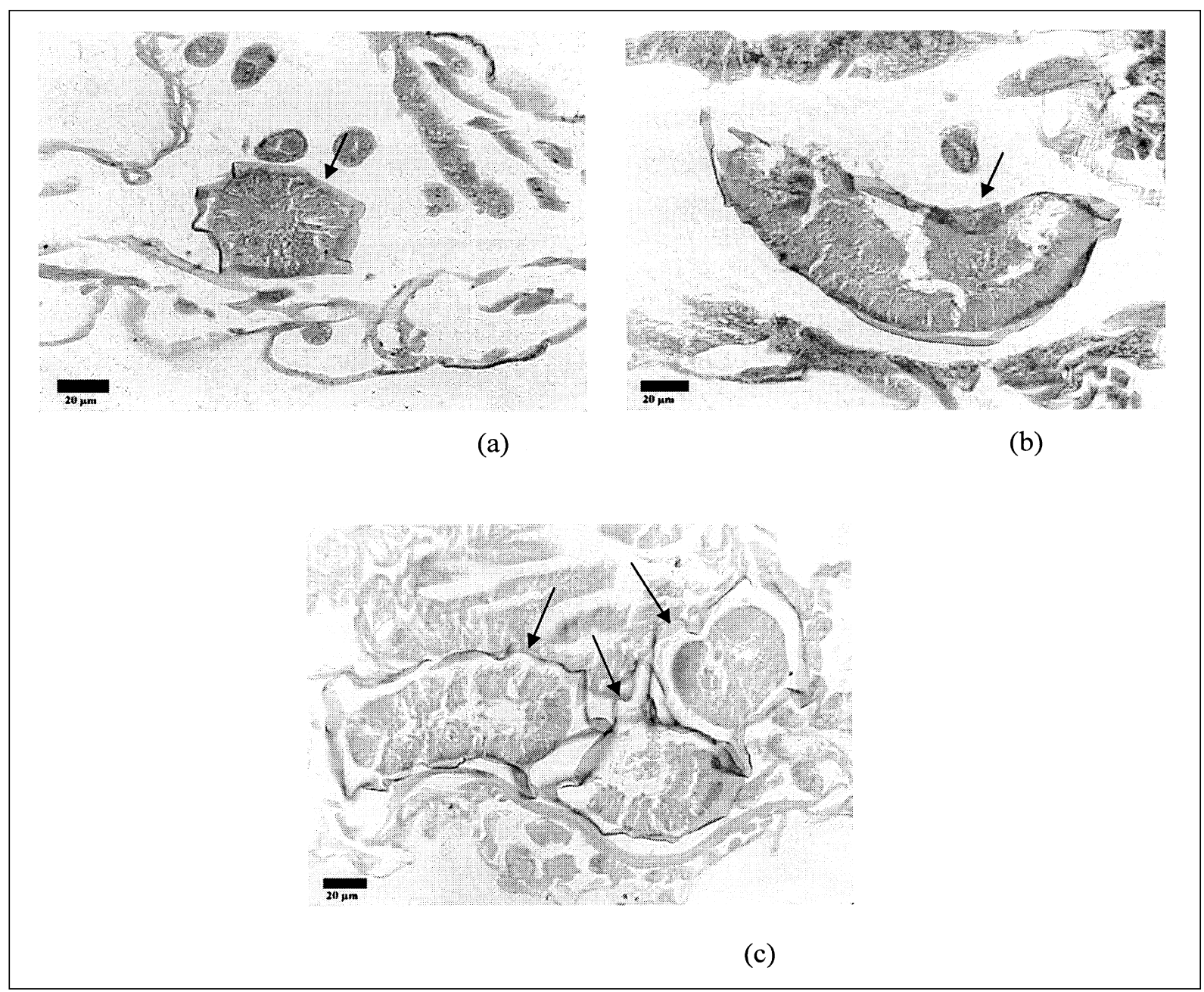

Figura 1 - Corte histológico mostrando: ovo de $\boldsymbol{C}$. flavicincta (seta) em posição transversal (a) e longitudinal (b) em relação ao comprimento do corpo de $\boldsymbol{S}$. frugiperda não infectada por B. thuringiensis aizawai; conjunto de três ovos de $\boldsymbol{C}$. flavicincta (setas) em lagarta de $\boldsymbol{S}$. frugiperda infectada por B. thuringiensis aizawai (c).

ovos do parasitóide no corpo da lagarta no momento da fixação do material, o tamanho desses ovos ficou em torno de $0,1 \mathrm{~mm}$ de largura (Figura 1a) e $0,2 \mathrm{~mm}$ de comprimento (Figura 1b). Foi verificada, ainda, a presença de mais de um ovo por lagarta (Figura 1c). Essas observações assemelham-se às de PATEL \& HABIB (1987), que apresentaram a descrição morfológica das diferentes fases de desenvolvimento de $\boldsymbol{C}$. flavicincta em $\boldsymbol{S}$. frugiperda.

A análise dos cortes histológicos evidenciou que não houve modificações aparentes nos ovos de $\boldsymbol{C}$. flavicincta após a ingestão de Bt aizawai por lagartas de $\boldsymbol{S}$. frugiperda, sendo que, nas figuras 1a e 1b, são apresentados ovos em lagarta não infectada $\mathrm{e}$, na figura 1c, ovos em lagarta infectada. Esta observação concorda com MAGALHÃES et al. (1998), que concluíram que, como a bactéria atua no intestino do inseto, é pequena a probabilidade de um parasitóide que se desenvolve num hospedeiro contaminado ter contato direto com as toxinas da bactéria.

Pode-se concluir que o uso de produto à base de Bt aizawai não afeta os ovos de C. flavicincta em lagartas de $\boldsymbol{S}$. frugiperda, porém novos estudos precisam ser realizados para verificação do efeito de cristais proteicos tóxicos sobre a fase larval do parasitóide no interior do corpo das lagartas de $\boldsymbol{S}$. frugiperda.

\section{AGRADECIMENTOS E APRESENTAÇÃO}

À Coordenação de Aperfeiçoamento de Pessoal de Nível Superior (CAPES), pela concessão da bolsa durante o curso de Doutorado.

Parte da tese apresentada pelo primeiro autor ao Programa de Pós-graduação em Fitotecnia (Fitossanidade), Universidade Federal do Rio Grande do Sul (UFRGS), Porto Alegre, RS, Brasil.

Ciência Rural, v.37, n.1, jan-fev, 2007. 


\section{REFERÊNCIAS}

ARANDA, E. et al. Interactions of Bacillus thuringiensis crystal proteins with the midgut epithelial cells of Spodoptera frugiperda (Lepidoptera, Noctuidae). Journal of Invertebrate Pathology, v.68, p.203-212, 1996.

BAUER, L.S. Resistance: a threat to the inseticidal crystal proteins of Bacillus thuringiensis. Florida Entomologist, v.78, n.3, p.414-443, 1995.

BEEGLE, C.C.; YAMAMOTO, T. Invitation paper (c.p. Alexander Fund): History of Bacillus thuringiensis Berliner research and development. Canadian Entomologist, v.124, p.587-616, 1992.

CRUZ, I. A lagarta-do-cartucho na cultura do milho. Sete Lagoas: EMBRAPA - CNPMS, 1995. 45p. (Circular Técnica 21).

CRUZ, I. et al. Efeito da idade de lagartas de Spodoptera frugiperda (Smith) (Lepidoptera: Noctuidae) no desempenho do parasitóide Campoletis flavicincta (Ashmead) (Hymenoptera: Ichneumonidae) e consumo foliar por lagartas parasitadas e não parasitadas. Anais da Sociedade Entomológica do Brasil, v.26, n.2, p.229-234, 1997.

DEQUECH, S.T.B. et al. Interação entre Spodoptera frugiperda (Lep., Noctuidae), Campoletis flavicincta (Hym., Ichneumonidae) e Bacillus thuringiensis aizawai, em laboratório. Neotropical Entomology, v.34, n.6, p.937-944, 2005.
FIUZA, L.M. Étude des sites récepteurs et de la toxicité des (-endotoxines de Bacillus thuringiensis Berliner chez les larves de la pyrale du riz Chilo suppressalis Walker, 1995. 181f. These (Doctorat-Sciences Agronomiques) - Ecole Nationale Superieure Agronomique de Montpellier, Montpellier.

MAGALHÃES, B.P. et al. Interações entre entomopatógenos, parasitóides e predadores. In: ALVES, S.B. (Ed.). Controle microbiano de insetos. Piracicaba: FEALQ, 1998. 1136p. p. 195-216.

NAVON, A. Control of lepidopteran pests with Bacillus thuringiensis. In: ENTWISTLE, P.F. et al. (Eds). Bacillus thuringiensis, an environmental biopesticide: theory and practice. Chichester: John Wiley \& Sons, 1993. p.125-146.

PATEL, P.N.; HABIB, M.E.M. Biological studies on Campoletis flavicincta (Asmead, 1890) (Hym., Ichneumonidae), an endoparasite of the fall armyworm, Spodoptera frugiperda (Abbot \& Smith, 1797) (Lepid., Noctuidae). Journal of Applied Entomology, v.104, p.28-35, 1987.

SILVA, F.M.A. et al. Parasitismo em lagarta-do-cartucho, Spodoptera frugiperda (Smith), na região do Triângulo Mineiro, MG. Anais da Sociedade Entomológica do Brasil, v.26, p.235-241, 1997.

VALICENTE, F.H. et al. Identificação através de PCR dos genes cry I de Bacillus thuringiensis Berliner eficientes contra a lagarta do cartucho, Spodoptera frugiperda (J. E. Smith) (Lepidoptera: Noctuidae). Anais da Sociedade Entomológica do Brasil, v.29, p.147-153, 2000. 